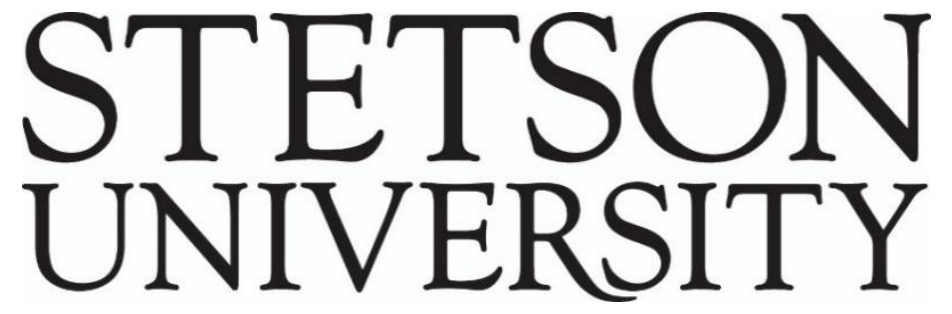

Voices of Reform: Educational Research to Inform and Reform

Volume $2 \bullet$ Issue $1 \bullet$ Article 7

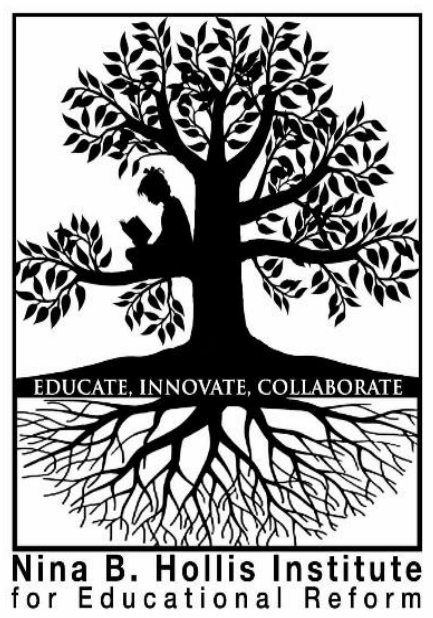

September 2019

\title{
Book Review: Ginicola, Smith, and Fillmore: Affirmative Counseling with LGBTQI+ People
}

Brigid Noonan

Nazareth College

Follow this and additional works at: http://www.voicesofreform.com

Recommended Citation

Noonan, B. (2019). Book review: Ginicola, Smith, and Fillmore: Affirmative counseling with LGBTQI+ people.

Voices of Reform, 2(1), 96-98. Retrieved from https://www.voicesofreform.com/article/10634-book-review-

ginicola-smith-and-fillmore-affirmative-counseling-with-lgbtqi-people doi: 10.32623/2.00009

http://dx.doi.org/10.32623/2.00009

Revisions

Submission date: May 21 ${ }^{\text {st }}, 2019$

Publication date: September $30^{\text {th }}, 2019$ 


\title{
Book Review: Ginicola, Smith, and Fillmore: Affirmative Counseling with LGBTQI+ People
}

\author{
Brigid Noonan $^{1}$ \\ ${ }^{1}$ Dean, School of Health and Human Services \\ Nazareth College, United States \\ bnoonan8@naz.edu
}

\section{Review}

Affirmative Counseling with LGBTQI+ is a comprehensive, practical and user-friendly text written specifically for clinicians and educators to engage and support the LGBTQI+ populations. Separated into four sections: I - Foundations; II - Counseling Considerations and Counseling Strategies; III - Specialized Populations; and IV - Emerging Issues; each chapter begins with an awareness of attitudes and beliefs checklist, asking excellent questions related to the particular topic, then introducing the reader to a specific case study, also related to the specific chapter. At this juncture, the author(s) of each chapter introduce the reader to the particular topic, with the chapter ending in Questions for Further Discussion, and Resources.

Building and developing knowledge, skills, and awareness as a clinician are a large part of what the editors and authors want the reader to increase as they think about the client(s) with whom they are working. In Section I - Foundations, the authors ask the reader to think about power and privilege when increasing their competencies in working with the LGBTQI+ population. As these competencies take shape, it is imperative that the history of oppression, bias, homophobia, transphobia, and other forms of discrimination are always kept in in the forefront. Additionally, being comfortable discussing the science of gender and affectional orientation is critical for the counselor in order to provide psychoeducation to clients and support systems. Moving into Section II - Counseling Considerations and Counseling Strategies, Chapter 3, the authors note how important it is for counselors to always keep the developmental stage of their clients in mind, and specifically the impact childhood and adolescence had on the LGBTQI+ individual, as having knowledge of that context will further assist the counselor in developing an appropriate intervention. Additionally, in this section, a chapter on affirmative counseling with LGBTQI+ individuals is particularly important as the field of counseling and therapy has shifted from shame- 
based therapy, otherwise known as sexual orientation change efforts (SOCE) and/or reparative therapy to a more culturally appropriate, competent, and respectful approach.

The American Counseling Association (ACA) has stated that the use of reparative therapy or SOCE is unethical and should not be practiced. Other fields, e.g., psychology and social work, have also found reparative therapy/SOCE to be unethical. Because of the oppression, discrimination, bias, and systemic heterosexism that LGBTQI+ individuals face, utilizing a more affirming and culturally-based model, appropriate for the client, is the ethical approach for counselors to take.

In Section III - Specialized Populations, each chapter addresses specific LGBTQI+ clients, and the authors note that "although the queer community is often aggregated into one population, it actually consist of multiple identities that are incredibly varied in their counseling needs" (p. 128). The importance of embracing the diverse arena that LGBTQI+ clients bring is emphasized in this section. The use of appropriate language when working with the LGBTQI+ client is imperative and must be addressed within the counseling relationship. Counselors cannot assume that the use of queer will be accepted, nor can they assume that the use of gay will be accepted. What is important is asking the client what they want. A common theme throughout the book is the marginalization that this population has experienced. Moreover, because of their experiences, and fear associated with discrimination, prejudice and bias, many LGBTQI+ clients will not disclose their identities to clinicians.

In Section IV, the authors point out that not only are LGBTQI+ individuals distinct, but each of these groups is itself diverse, whose members vary widely in age, race and ethnicity, immigrant status, geographic location, social background, religiosity/spirituality, and other demographic characteristics. They end the book with a chapter on advocacy and the importance being an ally plays in the lives of the LGBTQI+ client. As they state, it is an ethical obligation to advocate for clients who have been oppressed, discriminated and marginalized, as well as it is an ethical obligation for the counselor to continually work on building their knowledge, skills and awareness when entering a counseling relationship to ethically and respectfully work with their LGBTQI+ clients.

There is a wonderful glossary of terms, as well as problematic terms to avoid in the back for readers.

This book is written for mental health practitioners, as well as graduate students studying to become counselors/therapists. It will be an excellent addition to a library or resource room, as well as a guide for practitioners who want to specialize in working with the LGBTQI+ population. It engages the reader, emphasizing how important it is for practitioners to be cognizant of their values, and to have done their homework when working with the LGBTQI+ population.

\section{References}

Ginicola, M.M., Smith, C., \& Filmore, J.M. (Eds.) (2017). Affirmative counseling with LGBTQI+ people. Alexandria, VA: American Counseling Association. 389 pp. ISBN 9781556203558. 